\title{
HIV/AIDS prevalence, knowledge, attitudes and related behaviors among young people in Libreville, Gabon
}

\author{
Ndjiembi A. Christiane ${ }^{1}$, Zamba M. Roger ${ }^{2}$, Jacob Masika ${ }^{3}$, Yan Zhang ${ }^{1}$, \\ Zhang liang ${ }^{1^{*}}$ \\ ${ }^{I}$ School of Medicine and Health Management, Huazhong University of Science and Technology, Wuhan, Hubei, \\ 430030, China. \\ ${ }^{2}$ Ministry of Education, Libreville-Gabon. \\ ${ }^{3}$ Department of Medical Physiology, Faculty of Health Sciences, Egerton University, Kenya
}

\begin{abstract}
The few available data that exist show that the prevalence of HIV infection among adolescents in Gabon is increasing. This study aimed to assess HIV-related knowledge, attitudes and practices (KAPs) of high school and college students in Libreville, Gabon. A sample size of 601 students(258 males and 343females) aged between 12 and 24 years was selected by systematic random sampling. Results showed that half of the respondents were aware of HIV transmission through sexual intercourse (55.7\%), from mother to child (48.3\%) and through sharing needles or syringes (51.8\%). About $15.14 \%$ of students had an idea of unsafe practices related to HIV transmission. About 55.7\% of respondents reported to have positive attitude towards people living with HIV/AIDS. About $45.3 \%$ of the respondents reported willingness to study in a school with HIVpositive friends and $39.3 \%$ of the respondents reported that can attend a school with HIV-positive teachers. Only about $25.62 \%$ of the respondents who reported to engage in sexual activities used condoms. The study showed that students have inadequate information about HIV/AIDS transmission and prevention and therefore appropriate measures need to be urgently instituted to reduce spread of HIV/AIDS in this population.
\end{abstract}

Keywords: Attitudes - Behaviors -HIV/AIDS- knowledge- Students

\section{Global AIDS Epidemic}

\section{Introduction}

Worldwide, approximately 5 million of young people aged 15 to 24 years are living with Human Immunodeficiency Virus (HIV) that causes Acquired Immunodeficiency Syndrome (AIDS) as per 2009. According to new [1] estimates, 2 million adolescents (1.8 million to 2.4 million) between 10 to 19 years are living with HIV. Still, each day, more than 7000 people are newly infested with the HIV virus, including 1000 children [1].

Sub-Saharan Africa is the part of the world most affected by this scourge; it holds the record for the rapid spread of HIV/AIDS in the world [2]. Twenty countries in Sub-Saharan African accounted for an estimated 69 per cent of the word's new HIV infections among young people in 2009. Also, 1,100,000 girls and 620,000 boys aged 10-19 years were estimated to be living with HIV in Sub-Saharan African as per 2009. There were an estimated 700,000 new cases occurring among young people aged 15-24 years in 2009. Twentysix per cent of women aged 15-24 years and 33 per cent of men in Sub-Saharan African showed comprehensive knowledge of HIV/AIDs. According to the latest estimates, 14 per cent of girls and 11 per cent of boys aged 1519 had sex before the age of 15 years. Among women aged 20-24, the number is 17 per cent while among men of the same age group, it is about 9 percent [1].

\section{The AIDS epidemic in Gabon}

The prevalence of HIV infection in the adult population in Gabon was reported to be low in 2009 (5.2\%) compared to $2007(5.9 \%)$ [3]. Gabon is still in the range of countries where the prevalence rate is worrisome. SPECTRUM estimated that the total number of People Living with HIV (PLHIV) in Gabon was 46,051 in the year 2011 [4]. The prevalence of HIV infection in the age group 15 to 24 years is 4.8\% [5]. Internal migration of people including students who move to cities or urban areas after high school to continue their studies or to work is very common. These young people are away from their families for years at a time and very often visit commercial sex workers (CSWs) for sex. This increases the possibility of spreading HIV between them, and thereby to the general population [6].

Although people of any age and gender are susceptible to HIV, young people aged 15 to 25 years are more at risk of contracting it. According to the World Health Organization and the Joint United Nations Program on HIV/AIDS, youths are much more prone to HIV infection as a result of a lack of correct health 
information, indulgence in risky behaviors, and lack of access to adequate reproductive health services. Young people face greater challenges and more exposure to risks, including economic exploitation, changing lifestyles, global, regional and national conflicts, and the spread of sexually transmitted infections and HIV/AIDS [7]. Also another study found that socio-economic issues associated with poverty, including limited access to highquality health care; the exchange of sex for drugs, money, or to meet other needs; and higher levels of substance use can directly, or indirectly, increase HIV risk factors among women [8]. Any intervention targeted at young people before they are sexually active could prevent new HIV infections [7].

Increasing knowledge of HIV/AIDS can be a powerful means of fostering positive attitudes and building safe practices among populations. Hence, a clear understanding about knowledge, attitudes and practices (KAPs) among any population is very important for planning to control or prevent the spread of HIV. Information about HIV/AIDS-related KAPs has been reported by a number of researchers in different countries. Several studies have been conducted in Nigeria, Ghana and Botswana, African countries in the same SubSaharan region as Gabon, to investigate KAP levels among their youthful populations. These studies found that knowledge about the transmission of HIV was poor in senior high school students in Nigeria $(31 \%, 14.4 \%, 9.1 \%$ and $8 \%$ of the students studied identified sexual intercourse, blood transfusion, mother to child (vertical) transmission and intravenous drug use, respectively). Only $7.1 \%$ identified all of the listed four modes of transmission of HIV whilst $0.7 \%$ of the students identified all of the listed preventive methods [9]. A survey among adolescents aged between 10 and 19 years in Ghana reported sexual abstinence (78.1\%), condom use (72.7\%), fidelity to partner (72.5\%), not sharing needles (76.4\%) and reducing sexual partners $(56.7 \%)$ as important factors in preventing AIDS [10]. Nearly half of the participants from the school of Pune (India) believed that HIV can be contracted from toilet seats [11] and another study from Afghanistan reported that $53.2 \%$ of subjects believed that mosquito bites can transmit HIV [11, 12]. Negative attitudes toward people living with HIV (PLHIV) and sexual behaviours were also reported by another study [11]. In Botswana, a study showed disparities in HIV-related knowledge and behaviors among University of Botswana students. For example, whereas all students believed that all sexually active adults should know their HIV status through regular testing, only half perceived that HIV testing was common among their peers. The reasons for this discrepancy are unclear, but may be related with factors previously identified in Botswana and elsewhere in subSaharan Africa: concerns over breaches in confidentiality, pre-test counseling methods that frightened students, lack of knowledge of a local test site, fear of learning one's status, and lack of perceived HIV risk [13]. Another study from Botswana, reported that Teachings at the University health center about diseases and health prevention were appreciated by the study groups that had used that facility. In addition to increasing knowledge, it also appeared that the HIV/AIDS course improved students' attitudes toward HIV-positive people and even helped them change certain behaviors (e.g., limiting partners, using condoms correctly, and being tested for HIV) [14]. Although HIV/AIDS-related KAPs are reported in studies from other countries, there was no such information for school students in Libreville Gabon. Therefore, this study was conducted among high school and college students in Libreville Gabon to determine their level of KAPs regarding HIV/AIDS to provide theoretical and practical information to the nation policy making authorities.

\section{Study design, sampling and procedure}

\section{Methods}

This cross-sectional survey was conducted between $6^{\text {th }}$ and $15^{\text {th }}$ March 2009 in 14 public institutions ( 8 high schools and 6 CES) in Libreville, Gabon. Private and faith-based institutions were excluded from the study because students were on holiday during the time of the survey. Selected schools and colleges were chosen purposively in Libreville city, Estuary Province because this is area with highest HIV prevalence in the country. A total of 601 students, including girls and boys, aged 15 to 24 years were recruited. As there was no existing data on KAPs among high school and college students in Gabon, we calculated the sample size based on the estimate that $50 \%$ of students may have enough knowledge on HIV/AIDS. Precision was set at $10 \%$. For $\mathrm{P}$ value $0.05 \%$ and $80 \%$ power of the study, our expected sample size was 196 students. Fearing a high nonrespondent rate because of the sensitivity of the issue, our aim was to recruit 601 respondents. To obtain our desired target of 601 participants, we decided to recruit a set number of students from each school by choosing every $8^{\text {th }}$ student among boys and every $8^{\text {th }}$ student among girls as our final respondent through systematic random sampling. Based on the observation and history from the school records, students who were less than 15 years old and mentally or physically disabled were excluded. Blood was collected from students using EDTA tube for $(10 \mathrm{ml})$ for HIV testing. The Serum was analyzed using two rapid tests with confirmation by Western blot at Raphael Hospital by the Faculty of Medicine and Social Sciences of Omar Bongo University.

\section{Questionnaire}

The aim of the questionnaire was to obtain information on the level of HIV/AIDS-related KAPs of the respondents, as well as their sources of information on the issue. The questionnaire was developed by the 
researchers in consultation with experts in the field. We also reviewed the questionnaire developed by the global school-based health survey for developing countries and Family Health International's questionnaire on HIV/AIDS prevention during the questionnaire development [15, 16,17]. Our final questionnaire included questions relating to HIV knowledge, attitudes toward PLHIV and sexual practices, in addition to sociodemographic information. The questionnaire was divided into four parts. Part I focused on the sociodemographic characteristics of the respondents, including age, gender, school or college, religion and their sources of information about HIV/AIDS. Part II contained 15 knowledge-related items, which again were subdivided into two sections, with questions relating to transmission, and prevention and control of HIV/AIDS. We included both positively and negatively framed questions to assess their knowledge, as well as their perceptions about HIV/AIDS. Part III comprised 12 questions on attitudes towards PLHIV, which again included both positively and negatively framed questions. Finally, Part IV comprised 10 questions about practices related to HIV/AIDS, including sexual behaviors and use of condom. Before main data collection, the questionnaire was piloted with 20 students, testing for clarity, feasibility and appropriateness of the questions for the students. The questionnaire was developed and tested in French.

\section{Ethics statement}

Before data collection began, students were briefed about the purpose of the study and technical terminologies used in the questionnaire and were given guidance on how to fill questionnaire. The trained research assistants then distributed the self-administered questionnaire during the 40 minutes break of class. The students were assured that their responses would be kept confidential and they should not write their names on the questionnaires. Respondents were also informed that their participation was entirely voluntary and that they were free to decline to answer any question they felt like not answering. Written informed consent was obtained from all the participating students. Prior permission to conduct this study was obtained from the headmasters of the involved high schools or principles of the colleges. Moreover, this study was approved by the Gabon Health Sciences Research Committee, Ministry of Health.

\section{Statistical analyses}

Data were entered into a spreadsheet and exported to Statistical Package for the Social Science (SPSS) for Windows, version 18.0 software (SPSS Inc., Illinois, USA) for analysis. Descriptive statistics were used to describe demo-graphic characteristics and KAPs about HIV/AIDS. Numbers and percentages were used to present categorical data. Mean and standard deviation (SD) was used for normally distributed continuous data, and median (interquartile range, IQR) for non-normal continuous data. All tests were two-tailed, and $\mathrm{P}<0.05$ was considered significant.

To evaluate knowledge and attitude of the respondents, we asked them to answer "yes", "no" or "do not know" to every knowledge- and attitude-related question. For practices, options were only "yes" or "no". We assigned a score of 1 for a correct answer and 0 for a wrong answer for knowledge- and practicerelated questions, and 1 for every positive answer in the attitude section and 0 for negative answers. The scores were then summed up to generate an overall score for each participant. Levels of KAPs were then re-categorized depending on their total, mean and median score [10]. The scores of attitudes and practices were categorized into two segments based on their mean and median score: those scoring less than mean scores for attitude were classified as "negative" and those scoring equal and more than mean scores were classified as "positive", attitudes. As data for practice was not normally distributed, we used median as the cut-off. Accordingly, those scoring less than median scores for practice were classified as "risky" practices, and those scoring equal and more than median scores were classified as "safe" practices.

\section{Socio-demographic characteristics}

\section{Results}

The mean age of the 601 participants was 20.2 years (SD 6.3), ranging from 13 to 24 years of which $60 \%$ were undergraduates. Overall, $517(95.0 \%)$ of the respondents were Christians. The study revealed a female predominance of $57 \%$ among the students surveyed. A high number of respondents were from The school Léon Mba (26.3\%) (Table 1). All participants were living with parents and siblings.

TABLE1. Socio-demographic characteristics of the study population $(\mathrm{N}=601)$

\begin{tabular}{lcc}
\hline Variable & Number & \\
\hline Age & & \\
Mean \pm SD $=\mathbf{1 7 . 2} \pm \mathbf{6 . 3}$ years & & \\
Range $=\mathbf{1 2 - 2 4}$ years & 258 & 43 \\
Gender & 343 & 57 \\
Male & & \\
Female & & \\
\hline
\end{tabular}


HIV/AIDS prevalence, knowledge, attitudes and related behaviors among young people in Libreville,

$\begin{array}{lcc}\text { Religion } & & \\ \text { Christianity } & 517 & 95 \\ \text { Islam } & 18 & 3 \\ \quad \text { others } & 12 & 2 \\ \text { High Schools } & & 6.7 \\ \text { The school of M.Arissani } & 40 & 6.7 \\ \text { The school Nelson Mandela } & 40 & 13.1 \\ \text { The school P.I.Gondjout } & 80 & 16.6 \\ \text { The schoo Léon Mba } & 100 & 10.0 \\ \text { The school J.H.Aubame } & 60 & 10.0 \\ \text { The school J.B.Obiang } & 60 & 3.3 \\ \text { The school P.Emane.E } & 20 & 3.3 \\ \text { The school of excellence } & 20 & 3.3 \\ \text { Colleges } & & 3.3 \\ \text { CES L.Bigman } & 20 & 3.3 \\ \text { CES G.Anguile } & 20 & 10.0 \\ \text { CES A.Mba } & 20 & 6.7 \\ \text { CES Mabignath } & 60 & 3.3 \\ \text { CES R.Boukat } & 40 & \\ \text { CES Alenakiri } & 20 & \\ & & \end{array}$

\section{Knowledge of HIV/AIDS}

As illustrated in Table 2, all of the respondents had heard of HIV/AIDS. Overall, the knowledge about route of transmission of HIV was high for some factors and relatively low for other factors. Accordingly, 55.7\% of respondents knew that HIV can be transmitted through sexual intercourse. The majority of students were also aware that HIV can be transmitted through sharing needles or syringes, $48.3 \%$ from mother to child and $44.7 \%$ through blood transfusions. However, there was confusion about some routes of transmission. For example, only $41.0 \%$ of the participants correctly answered that "shaking hands" with PLHIV does not spread HIV. There was confusion about routes of transmission, for example, nearly half of respondents incorrectly thought that HIV could be transmitted by eating from the same plate, drinking from the same glass, wearing the same clothes and sharing the same toilet with PLHIV. Only about a third of the respondents correctly answered that mosquitoes do not transmit HIV.

Table 2 also summarizes the knowledge of the students about prevention of HIV. A satisfactorily high level of knowledge was reported by students when they were asked questions such as: Can HIV be prevented by not sharing needle or syringe? Can using condoms during sexual intercourse protect against HIV infection? Can HIV be controlled by sticking to a single partner? However, in response to the question whether "HIV can be controlled by having a blood test before marriage" only 314 (52.3\%) replied "yes".

TABLE 2. Knowledge regarding transmission and prevention of HIV/AIDS $(\mathrm{N}=601)$

$\begin{array}{lcc}\text { Questions with correct response } & \text { Number } & \text { \% } \\ \text { Knowledge about route of transmission } & 334 & (55.7) \\ \text { HIV can be transmitted by sexual intercourse (Yes) } & 290 \\ \text { HIV can be transmitted from mother to child (Yes) } & 311 & (48.3) \\ \text { HIV can be transmitted by sharing needle or syringe (Yes) } & 268 \\ \text { HIV can be transmitted by blood transfusion (Yes) } & 246 \\ \text { HIV can be transmitted by shaking hand (No) } & 239 \\ \text { HIV can be transmitted by eating and drinking from the same plate or glass of an } & 249 \\ \text { HIV-positive person (No) } & 305 \\ \text { HIV can be transmitted by wearing the same clothes of an HIV-positive person } & 407 \\ \text { (No) } & \\ \text { HIV can be transmitted by sharing a toilet with an HIV-positive person (No) } & 368 \\ \text { HIV can be transmitted through a mosquito bite (No) } & 416 \\ \text { Knowledge about prevention and control } & 434 \\ \text { HIV can be prevented by not sharing needle or syringe (Yes) } & 314 \\ \text { HIV can be prevented by properly using condom during sexual intercourse (Yes) } & (41.7) \\ \text { HIV transmission can be avoided by remaining faithful to a single partner (Yes) } & (50.7) \\ \text { HIV transmission can be avoided by a blood test before marriage (Yes) } & (67.7) \\ \end{array}$

\section{Attitudes toward PLHIV}

Overall attitudes of the high school students are illustrated in Table 3. The students exhibited positive attitudes to taking care of their HIV-positive relatives if they were ill and continuing friendships with HIVpositive friends. However, less than half of the students showed positive attitudes on issues such as: buying items from a HIV-positive shopkeeper or food seller; if an HIV-positive student should be allowed to continue her/his studying in school and if an HIV-positive teacher should be allowed to continue her/his teaching in school. 
HIV/AIDS prevalence, knowledge, attitudes and related behaviors among young people in Libreville,

TABLE 3. Attitudes towards people living with HIV/AIDS (N=601)

\begin{tabular}{ll}
\hline Questions with positive response & $\begin{array}{l}\text { Number (\%) } \\
\text { reporting the } \\
\text { specified responses }\end{array}$ \\
\hline If one of your relative, who is HIV positive, becomes ill, would you be willing to care for \\
her/him in your house or community? (Yes) \\
If your friend is HIV positive, would you continue your friendship with him/her? (Yes) \\
If a shopkeeper or food seller is HIV positive, would you buy items from him/her? (Yes) \\
If a student is HIV positive, she/he should be allowed to continue his/her studying in \\
school? (Yes) \\
If the teacher is HIV positive, she/he should be allowed to continue his/her teaching in \\
school? (Yes)
\end{tabular}

\section{Practices related to HIV/AIDS}

Table 4 demonstrates that $439(73.04 \%)$ of the school students had a history of sexual intercourse. One hundred and thirty (29.61\%) students said they were using condoms during sex, only $112(25.62 \%)$ used condom regularly during intercourse with casual partner. A quarter of the respondents who engage in sexual intercourse reported to use condom regularly during sexual intercourse with casual partner. About $2 \%$ of the tested respondents were found to be HIV positive and appropriate referrals were made for further tests and treatment. Most of the respondents $(40.1 \%)$ said that their most common source of information was the television, followed by friends $(39.2 \%)$. Less than one-fifth of the respondents were aware about HIV/AIDS from radio $(17.3 \%)$ and brochures $(3.4 \%)$.

TABLE4. Practices regarding HIV/AIDS

\begin{tabular}{|c|c|c|}
\hline Variables & Number & $\%$ \\
\hline Ever had sexual intercourse $(n=601)$ & 439 & 73.04 \\
\hline Ever use condom during sexual intercourse $(n=439)$ & 130 & 29.61 \\
\hline Use condom regularly during sexual intercourse with casual partner $(n=164)$ & 42 & 25.62 \\
\hline Use condom in the last sexual intercourse $(n=439)$ & 224 & 51.31 \\
\hline Ever drunk alcohol $(\mathrm{n}=186)$ & 165 & 89.22 \\
\hline Had sex when under the influence of alcohol $(n=112)$ & 35 & 31.13 \\
\hline Tested and found HIV positive $(\mathrm{n}=601)$ & 13 & 2.16 \\
\hline Tested and found HIV negative $(n=601)$ & 588 & 97.84 \\
\hline
\end{tabular}

\section{Discussion}

This is the first study on HIV/AIDS-related KAPs among high school students in Libreville, Gabon. This study reports an average-level of KAPs relating to HIV/AIDS. However, misconceptions about the routes of transmission of HIV/AIDS remain. In addition, only just over half of the students showed positive attitudes towards PLHIV. About two-third of the students reported prior sexual experience. Understanding about some important points of transmission of HIV, such as the belief that HIV can be transmitted by mosquito bites, along with shaking hands, sharing clothes, toilets and utensils with PLHIV. This indicates that students need more information and education about some points of routes of transmission. Again, similar misconceptions have been reported in other studies $[12,18,19]$. The majority of students knew that the use of condoms during sexual intercourse could prevent HIV. Similar findings were reported by previous studies $[10-14,12,18,19]$. These misconceptions may increase the likelihood of HIV spread.

Students exhibited mixed reactions to PLHIV. For example, they were reluctant to see an HIVpositive teacher continue to teach. Similar results were reported in several studies conducted elsewhere $[10,17,19]$. One study reported that about half of the respondents $(33 \% 46 \%)$ disagreed with PLHIV being able to enter schools, and said that they would not want to sit near PLHIV, or to shake hands with them [17]. However, nearly half of the respondents also said they were eager to show compassion towards PLHIV [20]. However, they still fear that having close contact with them might put them at risk of contracting HIV. This is illustrated by a reported willingness to maintain a friendship or to be taught by PLHIV but not wanting to sit with them in the classroom. These attitudes are important to consider when developing strategies to respond to HIV.

Discrimination against PLHIV might be an obstacle for the efficient propagation of awareness programmes [12], and voluntary counseling and testing for HIV. PLHIV should be equally respected and valued in the society. Adolescents need targeted counseling about safe practices by avoiding, for example, unprotected sexual relationships and exchange of syringes and needles. Two-third of high school students had a history of sexual intercourse, similar to the findings from other studies $[17,19,21,22]$. In this study, the first sexual contact was reported to be about the age of 13 which is lower compared to other studies in other countries [19,21,23-25]. Religious faiths discourages against premarital and extramarital sex, as well as homosexuality, but the young people seem to pay little attention hence the high number of youths who reports ever having 
sexual intercourse before marriage. Currently religious issues are important in Gabon which is among many countries that are trying to acknowledge these sexual behaviors in their governmental response.

Adolescents should be the focus of HIV/AIDS-related activities because this is the age when they become sexually active and are accessible through in-school education. Accurate HIV knowledge will support adolescents in making informed choices about their practices that may protect them from HIV transmission. In the present study about $2 \%$ of the respondents tested HIV positive and this may sound a warning and serve as a wakeup call to all stakeholders to aggressively address the issue if HIV prevention in this group. Sexual education in schools needs to be implemented soon. According to the Ministry of Health of Gabon, only 1 out of 2 young Gabonese aged 15-24 have a comprehensive knowledge on HIV in a country where the prevalence rate among youth aged $15-24$ is about $4.8 \%$, and $15 \%$ of youth have sexual relationships before the age of 15 [26]. In this study many adolescents and young people reported to engage in sexual intercourse without condoms. We found that less than half of the participants were using condoms consistently during sexual intercourse. This was consistent with other surveys in previous years [12,22,25]. In Gabon, young and unmarried people buying condoms can be a sensitive issue. Adolescents might be embarrassed about buying condoms from shopkeepers out of fear that the shopkeepers might inform their parents.

Although condoms are widely available in pharmacies, hotels, nightclubs and guest houses and kiosks in the neighborhoods, the precarious financial situation of young Gabonese and abject poverty limits their access to condoms which may be a major barrier to HIV prevention. Only about $25.62 \%$ of the respondents who engaged in sexual activities reported to use condom regularly with their partners. Some students said they were not comfortable using condoms during sex because they felt it might reduce their sexual pleasure. Sex education programmes grounded in evidence-based effectiveness are the cornerstones in reducing adolescent sexual risk behaviors and promoting sexual health [26]. In addition to providing accurate information about consequences of sexually transmitted infections (STIs), including HIV/AIDS [27,28], such programmes are most commonly implemented in school, which may reach a large number of teenagers [29].

There were several limitations to this study. First, we restricted this study to only one province and did not include out-of-school adolescents. This limits the generalizability of the study findings to other provinces and to all adolescents of similar age. Second, whilst HIV knowledge is important, it may not be the primary factor in explaining HIV transmission among young people. Many people have adequate knowledge about HIV but do not act on it due to a wide variety of social, cultural and economic constraints. Future studies to investigate these possible constraints could help to improve our understanding of HIV transmission. Third, there was the possibility of a significant social desirability bias leading to survey results that were not reflective of respondents' true attitudes and practices. This could potentially be due to social pressure to de-stigmatize HIV/AIDS and present oneself as aware of and proactive in HIV prevention. Finally, because of the selfadministered questionnaire, social desirability bias may have occurred. However, the anonymity of the questionnaires hopefully encouraged students to be honest in their responses. Despite all of these limitations, we believe this study might be a reasonable source of information for researchers and policymakers.

\section{Conclusion}

In conclusion, the results revealed that students did not have a good general level of knowledge HIV/AIDS. The study highlighted some misconceptions about HIV transmission, intolerant attitudes, stigma and discrimination towards PLHIV, and risky sexual practices, which need to be addressed. HIV/AIDS-related education programmes should include specific interventions to change practices, along with knowledge and attitudes. Future research involving nationally representative samples for both male and female, school attending and out-of-school adolescents could contribute substantially to HIV/AIDS prevention.

\section{Acknowledgements}

The authors acknowledge the precious contribution and cooperation of the participating students and teachers of all the studied schools and the Ministry of Health and Ministry of Education, Republic of Gabon. The study was supported in part by the Ministry of Health, Republic of Gabon in collaboration with UNAIDSGABON.

\section{REFERENCES}

[1] United Nations Children's Fund (UNICEF). Opportunity in Crisis: Preventing HIV from early adolescence to young adulthood (New York, United Nations, 2011).

[2] Report of the Secretary-General. Uniting for universal access: towards zero new HIV infections, zero discrimination and zero AIDSrelated deaths. (New York, UNAIDS, 2011).

[3] General Directorate of Prevention. National monitoring report of the declaration of commitment on HIV / AIDS (UNGASS) in 2008 (Libreville, Gabon, Ministry of Social Affairs, Solidarity, the protection of the widow and the orphan and the fight against AIDS, 2008).

[4] Directorate General for AIDS Prevention. National Report on the Response to HIV/AIDS (Libreville, Gabon, Ministry of Health,2012). 
[5] Emmanuel G. Regional Youth Forum CEMAC in the fight against HIV, 6th edition HIV cannot pass through the girl (Yaoundé, Cameroon, FREJES VI, 2012).

[6] Cai Y, Shi R, Shen T and . Pei B A study of HIV/AIDS related knowledge, attitude and behaviours among female sex workers in Shanghai China. BMC Public Health, 28(10),2010,377.

[7] Chen, Peter F. HIV/AIDS prevention among young people in East and South-East Asia in the context of reproductive and sexual health. Asia-Pac Popul, 23(1),2008, 7.

[8] National Center for HIV/AIDS, Viral Hepatitis, STD, and TB Prevention - Division of HIV/AIDS Prevention. HIV among Women. Centers for Disease Control and Prevention (CDC). 2013.

[9] Aomreore AA, Alikor EA, Nkanginieme KE. Survey of knowledge of HIV infection among senior secondary school 3 (SSS3) students in Port Harcourt. Niger J Med, 13(4), 2004, 398 - 404.

[10] Sallar AM. Correlates of misperceptions in HIV knowledge and attitude towards people living with HIV/AIDS (PLHIV) among inschool and out-of-school adolescents in Ghana. Afr Health Sci, 9(2),2009, 82 - 91.

[11] Kumar P, Pore P, Patil U. HIV/AIDS-related KAP among high-school students of municipal corporation school in Pune. An interventional study. Natl J Community Med,3(1), 2012,74-9.

[12] Mansoor AB, Fungladda W, Kaewkungwal J and Wongwit W. Gender differences in KAP related to HIV/AIDS among freshmen in Afghan universities. Southeast Asian J Trop Med Public Health. 39(3),2008,404-18.

[13] Stephens LL, Bachhuber MA, Seloilwe E, and Gungqisa N. HIV-Related knowledge, attitudes, and practice among educated young adults in Botswana. J AIDS HIV Res. 4(6), 2012, 159-164.

[14] Brown MS, Sebego M, Mogobe K, and Ntsayagae E. Exploring the HIV/AIDS-Related Knowledge, Attitudes, and Behaviors of University Students in Botswana. J Transcult Nurs. 19(4) 2008,317 -25.

[15] U.S. Agency for International Development (USAID). HIV/AIDS in the Mekong region Cambodia, Lao PDR. Thailand, \& Vietnam: current situation, future projections, socioeconomic impacts, and recommendations. (Washington, USA, USAID, 2003).

[16] National Committee for the Control of AIDS. National Strategic and Action Plan on HIV/AIDS/STI Control and Prevention 20112015. (Ventiane, Laos, Ministry of Health,2010).

[17] Hansson M, Stockfelt L, Urazalin M, and Ahlm C. HIV/AIDS awareness and risk behavior among students in Semey, Kazakhstan: a cross-sectional survey. BMC Int Health Hum Rights, $8,2008,14$.

[18] Koksal S, Namal N, Vehid S, and Yurtsever E. Knowledge and attitude towards HIV/AIDS among Turkish students. Infect Dis J Pakista, 14,2005,118-23.

[19] Tan X, Pan J, Zhou D, and Wang C. HIV/AIDS knowledge, attitudes and behaviours assessment of Chinese students: a questionnaire study. Int J Environ Res Public Health,4(3), 2007,248-53.

[20] Tavoosi A, Zaferani A, Enzevaei A, and Tajik P. Knowledge and attitude towards HIV/AIDS among Iranian students. BMC Public Health,4, 2004, 17

[21] Abruquah HH, Bio FY. HIV/AIDS. Knowledge, attitude and practice of school adolescents in the Kwaebibirem district of Ghana. J Sci Tech,28(2),2008,10-8.

[22] Kamala BA, Aboud S. Knowledge, attitudes and practices on HIV prevention among secondary school students in Bukoba rural, Kagera region-Tanzania. Dar es Salaam Med Students J,14(1), 2006,14-18.

[23] Jaiswal S, Magar BS, Thakali K, and Pradhan A. HIV/AIDS and STI related knowledge, attitude and practice among high school students in Kathmandu valley. Kathmandu Univ Med J (KUMJ), 3(1) 2005,69-75.

[24] Owolabi AT, Onayade AA, Ogunlola IO, and Ogunniyi SO. Sexual behaviour of secondary school adolescents in Ilesa, Nigeria: implications for the spread of STIs including HIV/AIDS. J Obstet Gynaeco, 25(2) 2005,174-8.

[25] Peltzer K, Promtussananon S. HIV/AIDS knowledge and sexual behavior among junior secondary school students in South Africa. J Soc Sci,1(1),2005,1-8

[26] UNAIDS. Gaming for HIV prevention: a public-private partnership in Gabon.(Gabon, UNAIDS, 2012)

[27] Wellings K, Collumbien M, Slaymaker E. Sexual behaviour in context: a global perspective. Lancet, 368(9548),2006,1706-28.

[28] UNFPA. Reproductive health education for young people (New York, UNFPA, 2003).

[29] Kirby D. Emerging answers: research findings on programs to reduce teen pregnancy (Washington, DC: National Campaign to Prevent Teen Pregnancy, 2001). 